\title{
How Large Can a Receptive Vocabulary Be?
}

\author{
ROBIN GOULDEN, PAUL NATION, and JOHN READ \\ Victoria University of Wellington
}

Studies of vocabulary size based on dictionary sampling have faced several methodological problems. These problems occur in trying to answer the following three questions: (I) How do we decide what to count as words? (2) How do we choose what words to test? (3) How do we test the chosen words? The present study attempts to overcome these problems and checks in several ways to see if the problems have been overcome. The results indicate that what were previously thought of as conservative estimates of vocabulary size are likely to be the most accurate. These estimates suggest that well-educated adult native speakers of English have a vocabulary of around 17,000 base words. This represents an acquisition rate of around two to three words per day.

\section{WHY STUDY VOCABULARY SIZE?}

In countries like Great Britain, the United States, Canada, Australia, and New Zealand, learners of English as a second language attend the same schools and universities as native speakers of English and follow the same classes. An obvious and striking difference between these two groups is in the size of their vocabulary. A young immigrant might arrive at school knowing almost no English words at all. A foreign student might enter an English medium university knowing only a few thousand words of English. What is the size of the vocabulary learning task facing such learners? How can they best be helped to manage it? How long will it take them to perform at a level comparable to that of native speakers? Diller (1978) put this last question another way: 'How long does it take to produce a bilingual?'

In one of the few studies in this area, Jamieson (1976) found that the rate of vocabulary increase was similar for five- and seven-year-old native speakers of English and learners of English as a second language who were in the same school system. This meant that the second language learners' rate kept pace with that of their native-speaking peers. However, the second language learners did not bridge the gap between their vocabulary size and that of the native speakers that already existed when they entered the school system.

In a more recent study, Cummins (1981) showed that the gap can be narrowed, but only after a number of years of English-medium education. $\mathrm{He}$ analysed the vocabulary test results of 1,210 foreign-born ESL students in the Toronto school system in relation to their age on arrival and length of residence in Canada. On the average, he found that children who had immigrated at the age of six or later took five to seven years to achieve scores that approximated those of native-born students at their grade level. As Cummins points out, this can have serious consequences for immigrant students because of the extent to 
which vocabulary knowledge influences performance on verbal IQ tests. These students may be wrongly diagnosed as having low academic potential on the basis of IQ tests administered to them during their first five years of residence in the host country.

Cummins relates his findings to a more general distinction between basic interpersonal communicative skills (BICS) and cognitive-academic language proficiency (CALP). According to this analysis, a major problem in assessing immigrant ESL learners is that they may rapidly acquire fluency in BICS within one or two years of arrival and thus give the impression that they have achieved a level of competence in the language equivalent to that of their native-speaking peers, whereas tests of vocabulary and reading comprehension reveal that they lack the underlying proficiency (or CALP) that is required to cope with academic study through the medium of their second language. Therefore, in this context, measures of vocabulary size-particularly the size of academic vocabulary-are important indicators of the ability of second language learners to achieve academic success.

Another perspective on the effect of inadequate vocabulary knowledge on academic performance is provided by Corson (1983), who suggests that the significance of the gap may be one not so much of size as of the type of vocabulary involved. His studies with native-speaking students of different social class backgrounds show 'a lexical bar' existing between the very frequent, largely monosyllabic, mainly Anglo-Saxon vocabulary of conversational English and the Graeco-Latin vocabulary of the English of academic study. The size and nature of the gap between learners on one side of the lexical bar and those on the other would have a direct influence on the type of help teachers would provide. If the gap was small for a particular group of learners, it might be more effective to encourage the learning of particular sets of words, like the university word list (Xue and Nation 1984). If the gap was large, concentration on vocabulary learning strategies and procedures would be more effective.

Investigations of vocabulary size then are of interest to teachers of English as a second language in that they can provide information about the size of the task facing second language learners and the most suitable ways of dealing with the task.

\section{PREVIOUS STUDIES}

Investigations of vocabulary size, particularly of native speakers, have been published since early this century. The most notable feature of these investigations is the enormous divergence among the results. The various estimates of the number of words known by college students and adults, for example, range from 3,000 words to 216,000 words (Fries and Traver 1960; Lorge and Chall 1963; Diller 1978).

These results are more striking if they are turned into daily estimates. Diller (1978), for example, estimates that secondary school children learn 20,000 words a year. This works out to be a rate of around 60 words a day! The lower estimates of vocabulary size, for example Diack (1975), convert to around three 
to five words a day. Clearly, direct teaching of vocabulary will be more significant if the lower estimates are nearer to the truth. If the higher estimates are more accurate, then other approaches are needed.

Thesie divergences between the estimates are the result of methodological problems involved in measuring vocabulary size (Thorndike 1924; Lorge and Chall 1963). By finding satisfactory solutions it is possible to reinterpret previous studies and develop tests that will give reliable and valid estimates. These problems occur in trying to answer the following three questions:

1 How do we decide what to count as words?

2 How do we choose what words to test?

3 How do we test the chosen words?

\section{HOW DO WE DECIDE WHAT TO COUNT AS WORDS?}

Studies of the size of receptive vocabulary have been based either on frequency counts or on dictionaries. The pros and cons of these methods have been discussed elsewhere (Lorge and Chall 1963; Nagy and Anderson 1984). In the case of dictionary-based studies, the estimation is done in the following way. First an estimate is made of the number of words in the dictionary. Then a representative sample of these words is drawn and learners are tested on their knowledge of each word. The proportion of words that they know in the test is taken as the proportion of words they know in the whole dictionary. For example, Diller (1978) assumed that the largest Webster's dictionary contained 450,000 entries, which is the figure given in the preface of the dictionary. He selected a sample of 1,000 words to be tested. When he administered the test to high-school seniors, the median score was 480 out of 1,000 , or 48 per cent. He thus calculated that their total vocabulary size was 216,000 words: 48 per cent of the 450,000 entries in the dictionary.

For such a calculation to be accurate, it is essential to estimate the number of words in the dictionary in the most reliable and valid way. This involves two types of decision. First, what is a word and what is not a word? For example, will abbreviations, names of persons, geographical place names, other names, prefixes, and suffixes be counted as words or not? Lorge and Chall (1963) showed that over 30 per cent of the basic entries in the Funk and Wagnall (1937) unabridged dictionary were of these types. Second, which words are to be considered as base words and which derived words? Clearly, in an estimate of vocabulary size, regarding mending, mend, mends, mended as different words will lead to inflated estimates. Similarly, regarding govern, misgovern, government, governor, and ungovernable as different words will also inflate the estimates.

\section{Word forms and learning}

Language teachers should be interested in learning, and decisions about what is included in a word family and what is not should be based on learning 
requirements. If a learner knows govern and is familiar with the prefix mis-, then misgovern requires little if any additional learning. For this reason govern and misgovern can be regarded as one word, or as one base word and a derived word. Row (in a row of chairs) and row (in row a boat) are homographs. They have the same form but quite different meanings. Knowing one meaning of row does not mean that minimal effort is needed to learn the other, so they would be regarded as two base words. This criterion of additional learning has implications for vocabulary teaching as well as for counting words. It is in the teacher's and learners' interests to reduce the number of words there are in English. This is done in two ways: by directing attention to the underlying concepts of words, and by making learners familiar with word parts. For example, the head forms in the head of a match, the head of the school, and the head on your body are homographs which can be considered as three different words or one word. In order to consider them as one word we need to show that there is one concept of head that is included in those three uses. If we can do this, then we have made learning head more interesting and economical and have reduced the number of different words in English. Similarly, explaining word meanings by using the meanings of the parts of the word reduces the number of different words by making new items appear as recombinations of already known parts.

Dictionaries tend to increase the number of words in a language rather than decrease them. For example, in some dictionaries words of a similar meaning but a different part of speech are listed separately. Thorndike (1924) and Williams (1932) found that the failure of vocabulary researchers to take account of homographs was a major sampling error in vocabulary size estimates. Derived forms of words with meanings closely related to a base word are often listed separately. Clearly it is not sufficient to rely solely on the dictionary to distinguish different words. Different entries and different words are not the same. Some information provided by the dictionary is of value, particularly for classifying abbreviations, proper nouns, compound words, archaic or obsolete words, dialect words, or slang. Decisions about base and derived words, and homographs with unrelated meanings, however, need to be made using outside criteria. In this way more realistic estimates of dictionary size and thus vocabulary size can be made.

Word types in Webster's Third New International Dictionary

In an attempt to evaluate previous estimates of vocabulary size and to provide a basis for the development of a test, a study was made of Webster's Third New International Dictionary (1961). This dictionary was chosen because it is the largest non-historical dictionary of English.

The preface to the dictionary says that it has a vocabulary of over 450,000 words. As noted above, Diller (1978) used this figure in his test of vocabulary size. It is only possible to get near a figure of 450,000 by counting every boldfaced entry in the dictionary. Many of these occur in the same line, for example, batten, battened, battening, battens, and represent inflected forms of 
alternative spellings. If same line entries are excluded, the dictionary contains around 267,000 entries (Dupuy 1974).

The words were classified into the following categories: base, derived, proper words (including compound proper words), compound words, and others. 'Others' include symbols, prefixes and suffixes, letters, abbreviations, alternative spellings, archaic words, and dialect words. Compound words consist of two or more words separated by a space or a hyphen (blue earth, blueeyed). Proper words are those in which the dictionary indicates as being usually, often, or sometimes capitalized (resedaceae n.pl, cap; puebla adj. usu. cap). Derived words are defined generally as words which require minimal extra learning. A corresponding base word must occur as a main entry in the dictionary. The meaning of the derived word must be clear from the meaning of the parts that make up the word or involve the minimum of extra learning. In some cases it was necessary to define as 'derived', words which had one derived meaning out of many, since in a test such words would have to be marked correct if the derived meaning was given as an answer. Irregular inflectional forms are included as derived words. Words consisting of common prefixes, for example, re-, attached to base words are marked 'derived'.

Nagy and Anderson (1984) set up a scale to distinguish base and derived words. The distinction between Nagy and Anderson's levels two and three was applied when distinguishing 'base' from 'derived'. All entries which were not included in the previous categories were, by elimination, 'base words'. Some entries with prefixes were classified 'base' although a specialized knowledge of the prefix, for example, pterygo-, may allow the meaning to be derived from the meaning of the parts. A word was classified as a base word if it was the least inflected form of a group of related words. When there was a choice between items of roughly similar length or inflection then nouns or verbs were counted as the base rather than adjectives or adverbs, for example, congruity would be considered as the base over congruent, congruous, congruism.

Considerable care was taken over the distinction between base and derived. The meaning relationship and the amount of extra learning required were always the main considerations. To clarify the classification of items further, here is a running set of items from one of the dictionary samples.

'cow This is the first in a set of homographs so it is acceptable. It was classified as a base word.

crampfish This is classified as a base word because there is no hyphen or space between cramp and fish and the meaning is not easily discovered from its parts.

${ }^{2}$ credit This is ignored because it is a subsequent homograph and the next item creditability is chosen. It is classified as derived because its meaning is clearly related to a base entry, credit.

crile The dictionary indicates that this is a dialect word chiefly Scot so it is classified under 'others'. 
crop-bound

crouchant

cry-..
This is classified as a compound word.

This means 'crouching' and is classified as derived.

This is a prefix and is classified under 'others'.

Note that wherever possible the criteria for deciding between the various types of words were based on forms or information provided in the dictionary. As we shall see in the next section of this article, there is sufficient evidence to show that the criteria were consistently applied.

\section{HOW DO WE CHOOSE WHAT WORDS TO TEST?}

In studies of vocabulary size, words have most commonly been selected by means of a spaced sampling procedure. This involves working through the dictionary from a randomly determined starting point taking words at a specified interval, for example, the first word on every fifth page, or every twelfth column. However, as Lorge and Chall (1963) pointed out in their analysis of the Seashore and Eckerson (1940) test, sampling from a dictionary needs to take account of the large amount of space given to high-frequency words. Furthermore, many entries in the dictionary are actually subsequent homographs of a previous entry. These represent high-frequency, often polysemous words which also have a large number of derived forms associated with them. For example, there are six entries in Webster's Third for fly, and its derivatives, including flyaway, fly-blown, flier, and flying constitute another large set of entries which occupy more than a page. Because such words occupy so much space and account for so many entries, the chance that they will be chosen in any spaced sample is high, and as a result a test based on this kind of sample will contain too many high-frequency items which will inflate the estimate of the learners' vocabulary size.

In a spaced sampling procedure, the amount of space taken up by a highfrequency word is less of a problem than the number of entries devoted to it. Dictionaries vary in the extent to which they create separate entries for homographs rather than incorporating them in a single entry. A comparison of the number of homographic entries for ten words (collective, crab, feather, fish, grow, hum, lop, man, presage, slough) in six dictionaries showed that for eight of the ten words Webster's Third had more or the same number of homographs as other dictionaries, and in the remaining two cases the Shorter Oxford English Dictionary (1973) had more. So homographic entries are as much, or more, of a problem for spaced sampling from Webster's compared with other dictionaries.

In the present study, three spaced samples were taken from Webster's Third. For Sample 1, the first new entry in every eleventh column was selected, unless it was a homograph of a previous entry, in which case it was ignored and the next item in the column was selected. For example, ${ }^{2}$ appassionato on page 103 would not have been selected because it is a subsequent homograph of ' appassionato. The next item appaumé would have been selected instead. The purpose of not choosing the subsequent homographs was to reduce, if not eliminate, the over-representation of high-frequency words in the sample. The 
interval of every eleventh column was used because it had been calculated that this would yield a sample containing about 700 words altogether and 200 base words. When the words in the sample were classified into the various categories identified above, it was found that the sample contained only 164 base words. Therefore, a second sample was drawn in the same way, except that the sampling interval was every tenth column. (As it turned out, this still produced only 181 base words.)

For Sample 3, it was decided to include subsequent homographs if they were the first new entry in the column but to keep a tally of them so that they could be treated as a separate category of items. In this case the sampling interval was again every eleventh column.

Table 1 gives the composition of the three samples. The subsequent homographs in Sample 3 have been excluded here to allow a more direct comparison with the results of the other two samples. The percentages in the table show a high degree of consistency in the results obtained from the three samples.

Table I: Results of three spaced samples of Webster's Third

\begin{tabular}{|c|c|c|c|c|}
\hline Classification & Sample I & Sample 2 & Sample 3 & Total \\
\hline Base & $164(22.7 \%)$ & $181(22.8 \%)$ & $147(26.1 \%)$ & $492(23.9 \%)$ \\
\hline Derived & $201(27.9 \%)$ & $227(28.6 \%)$ & $156(27.8 \%)$ & $584(28.1 \%)$ \\
\hline Proper & $61 \quad(8.5 \%)$ & $50 \quad(6.3 \%)$ & $60(10.7 \%)$ & $171 \quad(8.5 \%)$ \\
\hline Compound & $223(30.9 \%)$ & $252(31.8 \%)$ & $147(26.1 \%)$ & $622(29.6 \%)$ \\
\hline Others & $72(10.0 \%)$ & $83(10.5 \%)$ & $52 \quad(9.3 \%)$ & $207 \quad(9.9 \%)$ \\
\hline Total & 721 & 793 & 562 & 2,076 \\
\hline
\end{tabular}

We now have to deal with the question of what proportion of the total number of words in the dictionary are subsequent homographs. In Sample 3 there were 156 of them, which represents nearly 22 per cent of the sample. However, in another study which involved two spaced samples and three samples of all the words on a set of consecutive pages, Goulden (1984) arrived at the more conservative estimate that 15 per cent of the entries in Webster's Third were subsequent homographs. At least two thirds of them did not differ substantially in meaning from the first entry. For example, green has four entries. The first three have the same meaning but are different parts of speech, while the fourth entry is a dialect use meaning 'to yearn, to long for'. Therefore, in the present study the figure of 15 per cent has been used.

The next step is to translate the percentages from the samples in Table 1 into estimates of the number of entries in each category in the dictionary, based on the confirmed estimate that the total number of entries is 267,000 . First, the figures in Table 1 need to be adjusted to incorporate subsequent homographs as a separate category. If we take it that 15 per cent of the total entries belong in this new category, that means that there are 40,050 of them, i.e. 15 per cent of 
267,000 . When the 40,050 subsequent homographs have been subtracted from the total, the remaining 226,950 words can be assigned to the other categories according to the percentages in Table 1 . For example, base words comprised 23:9 per cent of the three samples combined, which gives us an estimate of 54,241 base words in the whole dictionary (i.e. 23.9 per cent of 226,950). This represents 20.3 per cent of the total of 267,000 entries. The complete set of estimates is given in Table 2.

Table 2: Proportions and totals of types of entries in Webster's Third

\begin{tabular}{lcc}
\hline Word type & $\begin{array}{l}\text { Estimated number } \\
\text { of entries }\end{array}$ & $\begin{array}{l}\text { Percentage } \\
\text { of entries }\end{array}$ \\
\hline Base & 54,241 & 20.3 \\
Derived & 63,773 & 23.9 \\
Proper & 19,291 & 7.2 \\
Compound & 67,177 & 25.2 \\
Others & 22,468 & 8.4 \\
Subsequent homographs & 40,050 & 15.0 \\
Total & 267,000 & 100.0 \\
\hline
\end{tabular}

Sampling: derived words

Because the distinction between base words and derived words is so important for this study, it is worth checking that the ratio of base to derived is valid. Table 3 gives the relative base and derived figures for three different studies of vocabulary in addition to the present study of Webster's Third. In the case of the Nagy and Anderson (1984) study, which was based on the American Heritage word frequency count (Carroll, Davies, and Richman 1971), the percentages in the table were calculated by re-arranging their categories to match those used in the present study. The Seashore and Eckerson (1940) study was based on Funk and Wagnall's (1937) unabridged New Standard Dictionary of the English Language. Seashore and Eckerson followed the dictionary maker's classification of base and derived words. The figures for the Shorter Oxford Dictionary were obtained by the present authors in a sample of words from the English Word Speculum (Dolby and Resnikoff 1967).

Table 3 shows that the classification into base and derived in the Webster's Third study gets considerable support from other studies. The exception is the Shorter Oxford study. A comparison of entries in Webster's Third and the Shorter Oxford shows that the Shorter Oxford includes some derivatives as part of the main entry while Webster's Third is more likely to list them as separate entries.

A study of Webster's Third by Dupuy (1974) provides some confirming evidence for the proportion of words classified as compound words and proper words. After we adjusted Dupuy's percentage to account for the different criteria he used to determine his total figure (he deliberately excluded 
Table 3: Relative proportions of base and derived words in several studies

\begin{tabular}{lllll}
\hline Word type & $\begin{array}{l}\text { Nagy and } \\
\text { Anderson } \\
(1984)\end{array}$ & $\begin{array}{l}\text { Seashore and } \\
\text { Eckerson } \\
(1940)\end{array}$ & $\begin{array}{l}\text { Shorter } \\
\text { Oxford } \\
\text { English } \\
\text { Dictionary }\end{array}$ & $\begin{array}{l}\text { Webster's } \\
\text { Third }\end{array}$ \\
\hline Base & $48 \%$ & $45 \%$ & $54 \%$ & $46 \%$ \\
Derived & $52 \%$ & $55 \%$ & $46 \%$ & $54 \%$ \\
\hline
\end{tabular}

subsequent homographs and prefixes from his total), it was found that compound words made up 29 per cent of the total and proper words made up 9 per cent of the total. These figures are very close to our figures of 25.2 per cent and 7.2 per cent.

\section{Word frequency and sampling}

The three Webster's Third samples contain a total of 492 base words. In order to make a one-percent sample of the base words in Webster's Third, 50 more words were selected by means of spaced sampling. These were added to the list, making a total of 542 base words (one percent of the 54,241 in Table 2).

It was necessary to check that the procedure of ignoring subsequent homographs during sampling achieved the intended result of producing a sample from Webster's Third which contained a suitable number of high frequency words. This was done by seeing how many items in the sample occurred in Thorndike and Lorge's (1944) word frequency list. Before the check could be made, the Thorndike and Lorge list itself was analysed to find the number of base words it contains. Table 4 gives the results. The base words in Thorndike and Lorge are actually under-represented in the one-percent sample of Webster's. A total of 139 Thorndike and Lorge words was expected but only 123 words from the list occurred in the Webster's sample. This underrepresentation was evenly spread between the first 10,000 and the second 10,000 levels of Thorndike and Lorge.

Table 4: Types of words in Thorndike and Lorge's (1944) list of 30,000 words

\begin{tabular}{lccc}
\hline Type & $\begin{array}{l}\text { Items in } \\
\text { sample }\end{array}$ & $\begin{array}{l}\text { Percentage of } \\
\text { toral }\end{array}$ & $\begin{array}{l}\text { Estimated totals } \\
\text { in Thorndike } \\
\text { and Lorge }\end{array}$ \\
\hline Base & 139 & 46.3 & 13,900 \\
Derived & 118 & 39.3 & 11,800 \\
Proper words & 39 & 13.0 & 3,900 \\
Abbreviations, etc. & 4 & 1.3 & 400 \\
Total & 300 & 100.0 & 30,000 \\
\hline
\end{tabular}


It is important that the high-frequency words are not over-represented or under-represented because these are the words most likely to be known. To take account of this, 16 words at suitable levels were randomly selected from Thorndike and Lorge and added to the Webster's list. Seventeen other items were dropped from among the lowest frequency words to keep it as a one per cent sample of Webster's Third.

The 542 words were now a representative sample of the base words in Webster's Third.

Bringing Webster's Third up to date

Webster's Third was published in 1961. The most recent addition to it, entitled 9,000 Words (1983), includes most of a previous addendum, 6,000 Words, new material for the 1981 addendum, and items added since then. An analysis was made of the first word on every second page of 9,000 Words, starting with page two and omitting pages where a new letter of the alphabet began (a one-percent sample of the 9,000 words). Twelve of the 90 words in the sample had been marked by the compilers as new senses of words already in Webster's Third (for example, bent $=$ dishonest, $h a w k=$ one who wants a war, pill $=$ contraceptive pill). One of the 90 was a homograph with a meaning unrelated to the form already in the dictionary (camp as an adjective). Fifteen of the 90 words were derivatives of words already in Webster's Third (for example, antiepileptic, brassware, buttondown, corotate). Three were proper words (for example, Chinese fire drill), and 30 were compound words (for example, black nationalist, command module, credibility gap). The remaining 29 words were classified as base words. They included aeroplankton, aliesterase, anamestic, astrochemistry, and barf. Nineteen of them were clearly technical terms. All of the 29 words were added to the Webster's list, making a total of 571 words.

Table 5: Word types in 9,000 Words

\begin{tabular}{lrr}
\hline New base words & 29 & $32 \%$ \\
$\begin{array}{l}\text { Homographs of } \\
\text { previous entries in }\end{array}$ & & \\
$\quad$ Webster's Third & 13 & $15 \%$ \\
Derived words & 15 & $17 \%$ \\
Proper words & 3 & $3 \%$ \\
Compound words & 30 & $33 \%$ \\
Total & 90 & $100 \%$ \\
\hline
\end{tabular}

Words excluded from testing

Proper words, compound words, derived words, and a variety of items classified under 'others' have been excluded from the test list created from this study. There are four reasons for this exclusion.

(1) Dictionaries differ considerably in the way they deal with compound words and proper words, both in their policies of inclusion and place of inclusion. For 
example, if we look at page 197 of the Shorter Oxford, which includes the items from bittacle to black, and compare the same range of items in Webster's Third, we find that Webster's Third includes 36 compound words which do not occur at all in the Shorter Oxford. The Shorter Oxford includes six compound words which are not in Webster's Third. All of the Shorter Oxford compound words are listed under the headword.

Page 365 of the Shorter Oxford, which runs from coindicate to cole-tit, contains no capitalized proper words, while the equivalent range in Webster's Third contains 16 proper words. The Shorter Oxford's attitude to proper words is clear from the following quotation from page $\mathrm{x}$ of the Preface:

In addition to and interpenetrating the common vocabulary with all its ramifications and outliers, there is a vast number of proper names, which either themselves acquire connotative value or give rise to derivatives which take their place among the ordinary words of the language.

Clearly, proper words are not seen as being ordinary words. Lorge and Chall (1963) have a similar opinion.

(2) Derivatives, abbreviations, alternative spellings, inflected words, some proper words, and a large proportion of compound words do not represent a significant extra learning burden. The distinction between derivatives and base words was made with this as a guide. About one-fifth of the proper words and three-quarters of the compound words can be classified as derivatives of these two classes. This means that in Webster's Third base proper words account for about 16,000 of the 267,000 entries, and base compound words (compound words where the first member of the compound does not have a separate entry in the dictionary) account for about 17,000 entries. Table 6 lists the nonderived entries in Webster's Third. Of these 113,161 base items, which all

Table 6: Base words and other types of base items in Webster's Third

\begin{tabular}{lcc}
\hline Word types & $\begin{array}{l}\text { Estimated number } \\
\text { of entries }\end{array}$ & $\begin{array}{l}\text { Percentage } \\
\text { ofentries }\end{array}$ \\
\hline Base words & 54,241 & 20.3 \\
Base proper words & 16,000 & 6.0 \\
Base compound words & 17,000 & 6.4 \\
$\begin{array}{l}\text { Other } \\
\text { abbreviations }\end{array}$ & 9,900 & 3.7 \\
$\quad$ word parts & 2,670 & 1.0 \\
$\begin{array}{l}\text { Subsequent homographs } \\
\quad \text { with unrelated }\end{array}$ & & \\
$\quad$ meanings & 13,350 & 5.0 \\
Total & 113,161 & 42.4 \\
\hline
\end{tabular}


represent new learning for a native speaker, only a one per cent sample of the 54,241 base words was chosen for testing.

(3) -It is important that the sample of words to be tested represents the words in the dictionary as closely as possible. Therefore the larger the sample, the better it is. With a one per cent sample of Webster's Third and 9,000 Words, the test list contains 571 items. The addition of other word types would increase the number of items in the test list to an unmanageable level.

(4) The main aim of this study is to determine the potential size of a native speaker's vocabulary. Because the frequencies of the various word types in Webster's Third are provided here, it is possible to make rough estimates of other groupings of word types by adding appropriate proportions of the desired word types to the base scores.

\section{HOW DO WE TEST THE CHOSEN WORDS?}

Now that we have a representative sample of words in the language, we need a method of finding out how many of the words people know. Before discussing how to use our Webster's Third sample for this purpose, let us look at the approach to vocabulary testing adopted by Diack (1975) in his book Wordpower: Your Vocabulary and its Measurement. Diack's work is interesting not only because of the testing procedure he used, but also because his way of sampling the words seems to produce relatively conservative estimates of vocabulary size that are much closer to our estimates than those of other investigators.

Diack prepared a set of 50 tests of 60 words each, based on an analysis of the Concise Oxford, Everyman's English Dictionary, and Chambers' Twentieth Century Dictionary. He also reported making use of the Thorndike and Lorge (1944) word list. The tests are divided into six frequency levels; each level represents 6,000 words and so each test item represents 600 words. Here is an example.

Test Number 24

Level 1
1 asphalt
2 carol
3 desert
4 encyclopaedia
5 oblong
6 paragraph
7 rafter
8 scale
9 scarcity
10 trapeze

\section{Level 2}

11 asterisk

12 centigrade

13 density

14 estuary

15 negative

16 perforated

17 radius

18 section

19 solitary

20 superfluous
Level 3

21 absorbent

22 carnage

23 deluge

24 eliminate

25 negotiate

26 parole

27 recalcitrant

28 rudimentary

29 stringent

30 translucent 
Level 4

31 acrimony

32 bauxite

33 cachet

34 denouement

35 egregious

36 obeisance

37 paradox

38 rationale

39 sacrosanct

40 zany
Level 5

41 anabaptist

42 chiaroscuro

43 dragoman

44 eidolon

45 nenuphar

46 parallax

47 parang

48 recalescence

49 rococo

50 subpoena
Level 6

51 alburnum

52 cacique

53 dunnage

54 enclitic

55 niello

56 paraheliotropism

57 radula

58 rocambole

59 surrebutter

60 talus

Based on his extensive use of the tests with various groups in Britain, Diack reports that people's vocabulary level depends primarily on their level of education, but it is also influenced by 'wide reading and wide contacts with life' $(1975: 12)$. He says that adults with a secondary education are generally at Level 3 (12,000-18,000 words). To reach Level 4 (18,000-24,000 words) normally requires either a university education or a lively mind and a wide range of reading. Those at Level 5 (24,000-30,000 words) are 'among the most widely read in the country. They are to be found in the top echelons of their professions or heading in that direction' (op. cit.: 11). Diack doubts the reliability of the tests beyond Level 5 but he suggests that there are only a few people at Level 6 .

A comparison of five of Diack's tests with the Thorndike and Lorge list reveals that 7 or 8 of the 10 words at Level 4 in Diack's tests are in the Thorndike and Lorge list. Level 5 in Diack's test includes 4 words out of 10 which are in Thorndike and Lorge. According to Diack, Level 4 represents a vocabulary of 24,000 words. Apparently when dividing words into levels, Diack relied on the frequency levels in Thorndike and Lorge, and he did not take account of the large number of derived words in Thorndike and Lorge which are already represented by base words in the list. Our analysis of Thorndike and Lorge showed that, of the 30,000 items in the list, only 13,900 are base words. To adjust scores on Diack's test on the basis of our Thorndike and Lorge analysis, it is therefore necessary to multiply a learner's score on Levels 1 to 4 by 0.46 or $9 / 20$, or roughly, to reduce it by half.

So, the fault of Diack's tests is that each of his 6,000 word levels does not represent 6,000 words because: (1) he did not accurately estimate the number of base words he was working with and did not make a random sample with appropriate precautions, and (2) he was misguided by the frequency levels in Thorndike and Lorge because he did not allow for derivatives and proper words in that list. However, because his estimate of the number of base words was near a sensible figure, the results of his tests are not wildly misleading, as other studies have been.

Let us now focus on the testing procedure that Diack sets out in his book. It is designed for self-assessment, along the lines of a 'Test Your Own IQ' book. Readers work through one of the tests, beginning at Level 1 . When they come to 
words that they do not know or are not sure of, they write down the numbers of those words and continue until they have written ten numbers. Then they stop and go back over the last five words that were thought to be known. For each of these five words, some kind of definition has to be written:

You can show your knowledge of the word by giving a synonymous word or phrase, by using it in a sentence that demonstrates your knowledge, or you can do it by diagram or sketch. (Diack 1975: 6)

The answers are then checked with a dictionary. If all or most of the five words are correct, it is assumed that all of the previous words that were thought to be known were in fact known and so the score is simply the total number of words known (after subtracting any of the five words that were wrong). In order to improve the reliability of the procedure, Diack recommends that people should take at least three of the tests and use the average score as the basis for estimating the size of their vocabulary, which is calculated by multiplying the average score by 600 .

Diack's procedure is an example of the most straightforward method of measuring knowledge of words: a 'yes/no' or checklist approach, in which the respondents are simply asked to indicate whether they know each word or not. This method has been used in vocabulary research for a long time, especially in studies of the vocabulary size of school children (for example, Sims 1923; Tilley 1936), although there have been continuing doubts about its validity. There are at least two questions that need to be addressed in using this method:

(1) What do we mean by 'knowing a word'? The investigator has to indicate simply and clearly to the respondents how they should decide whether they know a word or not. Does it mean that one has seen the word before, without perhaps knowing what it means? Or is it necessary to be able to give a dictionary-type definition of the word? What if one thinks that one knows the meaning but is not sure? Diack required his respondents to be fairly sure that they knew at least one meaning of the word, though he allowed them to express their knowledge in various ways; they did not have to compose a dictionary definition of the word.

(2) How can we detect whether the respondents have a tendency to overrate the ${ }^{i .}$ knowledge of the words? Even with a clear explanation of the criterion for knowing a word, it is likely that some respondents will tend to say 'yes' to more words than they really know. In recent years several researchers (Anderson and Freebody 1983; Nagy, Herman, and Anderson 1985; Meara and Buxton 1987; Meara and Jones 1987) have found a way of detecting this by including a good proportion of plausible non-words in their vocabulary lists. If respondents say that they know a number of the non-words, this indicates that they tend to overrate their vocabulary knowledge, and their scores can be reduced accordingly. This procedure has been used in studies with schoolchildren and second language learners, but such a check may not be so necessary in the case of adult native speakers. In Diack's tests, the last five 'known' words are 
checked. If all or most of them are wrong, he suggests that further checking of earlier words should be done in order to get a more realistic score. In addition, such a person should take some more of the tests and be more conservative in judging which words she or he knows.

In fact, experience with both the Diack tests and our sample (see Appendix 1) shows that the problem words form only a small proportion of the words being tested. If the words in the sample are arranged in order from most frequent to least frequent, there will be a certain number of words at the beginning that are all known by a native speaker, while many of the low-frequency words will be totally unfamiliar. For example, Diack (1975:20) reports that, when he had to give his tests to adults within a limited time, he would ask them to begin at Level 3 , because he knew that he could assume knowledge of the first 20 words. On the other hand, he found that very few people knew more than the odd word at Level 6 . Similarly, everyone knows the very common words at the beginning of our list, but we expect that well over half of the words in the sample will be completely unknown to native speakers. Thus, the doubtful words are those in the transitional section of the list between the two extremes. Any check of understanding is most profitably done on words in this intermediate section of the list.

To prepare the Webster's Third sample for testing, the words were put in order of frequency. For the more common words, this was based on Thorndike and Lorge (1944). Next came words that were not listed in Thorndike and Lorge, but which could be found in Webster's Collegiate Dictionary (1979). The remaining words (not in either Thorndike and Lorge or Webster's Collegiate) were placed at the end of the list. As a result, some words which are relatively familiar to native-speaking adults in New Zealand came well down the list among much less common words. Therefore words such as footage, glaucoma, cockup, geisha, weta, golliwog, ravioli and detente were moved to higher positions on the list in recognition of their frequency in contemporary usage.

The complete list was then divided into two parallel halves and tested with a small group of native speakers. They were asked to look at the words in the lists and indicate with a tick those words that they felt confident they knew and to put a question mark next to those they were not sure about. Their responses showed that a large number of the words were not known. On the basis of their responses the complete list was divided into two sections, one section of 250 words containing the most frequent words and the known low-frequency words. This was later subdivided into five equivalent tests each containing 50 words (see the Appendix). The remaining 221 words in the Webster's Third sample are included in the Appendix in a list titled 'Words in the Webster's Third sample that are not likely to be known'.

If each of the fifty-item tests are used separately' each item represents 500 words, so the number of items known in a test should be multiplied by 500 to get a total base vocabulary size score. If all five tests are sat, then the scores for all the tests should be added together and multiplied by 100 . People gaining a score 
above 15,000 words on these tests should also check the list of words not likely to be known. Each item represents 100 words.

The procedure for taking the five tests is fairly closely modelled on that of Diack. One difference in our test is the use of the question mark by respondents to mark words that they are not sure about. This was adopted partly for psychological reasons (many respondents find it more satisfying to have that response available) and also to guide the respondents to doubtful words when they check the list a second time.

The five fifty-item tests were given to a group of 20 native speakers, all of whom were university graduates over the age of 22 . Their average scores on the five tests ranged from 13,200 to 20,700 with a group average of 17,200 .

\section{CONCLUSION}

The present study leads us to the following conclusions:

(1) Using the largest non-historical dictionary available and allowing for some recent additions to the language, there are less than 58,000 base words to draw on for a vocabulary test. The majority of these base words are unknown to most native speakers of English.

(2) If proper words, compound words, affixes, and homographs with unrelated meanings are also included as base items, then there are just over 110,000 base items in Webster's Third. Clearly, estimates of the vocabulary size of adult native speakers which credit them with vocabularies of 216,000 words (Diller 1978) or 80,000 words (Miller and Gildea 1987) are greatly inflated. It is more likely that the average educated native speaker has a vocabulary of around 17,000 base words and has acquired them at the average rate of about two to three words per day.

(3) If native speakers do in fact acquire vocabulary at this relatively slow rate, it would seem that for second language learners direct teaching and learning of vocabulary is a feasible proposition. This could be done in a variety of ways (Nation 1990). Because around 66 per cent of the low frequency words of English come from French, Latin, or Greek, the use of word parts as mnemonic devices is a useful procedure. Similarly research on the keyword mnemonic techniques (Pressley et al., 1982) has demonstrated its value as a strategy for improving direct vocabulary learning. There is a wide range of vocabulary learning activities using words in sentence contexts. These include exercises using code, selective cloze exercises, and the use of texts with glossaries or direct teacher explanation. These activities, combined with large amounts of extensive reading accompanied by practice in guessing words from context, would allow second language learners to develop their vocabulary at a rate well above that of most native speakers.

(Revised version received February 1989) 


\section{REFERENCES}

Anderson, R. C. and P. Freebody. 1981. 'Vocabulary knowledge' in J. T. Guthrie (ed.): Comprehension and Teaching: Research Reviews. Newark: International Reading Association.

Anderson, R. C. and P. Freebody. 1983. 'Reading comprehension and the assessment and acquisition of word knowledge.' Advances in Reading/Language Research 2: 231-56.

Campion, M. E. and W. B. Elley. 1971. An Academic Vocabulary List. Wellington: NZCER.

Carroll, J. B., P. Davies, and B. Richman. 1971. The American Heritage Word Frequency Book. New York: Houghton Mifflin.

Clarke, D. F. and I. S. P. Nation. 1980. 'Guessing the meanings of words from context: strategy and techniques.' System 8: 211-20.

Corson, D. J. 1983. 'The Corson measure of passive vocabulary.' Language and Speech 26: 3-20.

Cummins, J. 1981. 'Age on arrival and immigrant second language learning in Canada: a reassessment.' Applied Linguistics 2: 132-49.

Diack, H. 1975. Test Your Own Wordpower. St. Albans: Paladin.

Diller, K. C. 1978. The Language Teaching Controversy. Rowley, Mass.: Newbury House.

Dolby, J. L. and H. L. Resnikoff. 1967. The English Word Speculum. The Hague: Mouton.

Dupuy, H. J. 1974. The Rationale, Development and Standardization of a Basic Word Vocabulary Test. Washington, DC: US Government Printing Office.

Fries, C. C. and A. A. Traver. 1960. English Word Lists. Ann Arbor: George Wahr.

Goulden, R. 1984. 'Measuring Vocabulary Size.' Unpublished BA Hons. research paper.

Jamieson, P. 1976. The Acquisition of English as a Second Language by Young Tokelau Children Living in New Zealand. Unpublished Ph.D. thesis, Victoria University of Wellington.

Lorge, I. and J. Chall. 1963. 'Estimating the size of vocabularies of children and adults: an analysis of methodological issues.' Journal of Experimental Education 32: 147-57.

Meara, P. and B. Buxton. 1987. 'An alternative to multiple choice vocabulary tests.' Language Testing 4: 142-51.

Meara, P. and G. Jones. 1987. 'Tests of vocabulary size in English as a foreign language.' Polyglot 8: 1-40.

Merriam-Webster. 1983. 9,000 words. Springfield, Massachusetts: Merriam-Webster Inc.

Miller, G. A. and P. Gildea. 1987. 'How children learn words.' Scientific American 257 3: $86-91$.

Nagy, W. E. and R. C. Anderson. 1984. 'How many words are there in printed school English?' Reading Research Quarterly 19:304-30.

Nagy, W. E. and P. A. Herman. 1984. 'Limitations of vocabulary instruction.' Technical Report, Center for the Study of Reading, University of Illinois 326.

Nagy, W. E., P. Herman, and R. C. Anderson. 1985. 'Learning words from context.' Reading Research Quarterly 20: 233-53.

Nation, I. S. P. 1990. Teaching and Learning Vocabulary. New York: Newbury House. New Standard Dictionary of the English Language. 1937. New York: Funk and Wagnall. 
Pressley, M., J. R. Levin and H. D. Delaney. 1982. 'The mnemonic keyword method.' Review of Educational Research 52: 61-91.

Seashore, R. H. and L. D. Eckerson. 1940. 'The measurement of individual differences in.general English vocabularies.' Journal of Educational Psychology 31: 14-38.

Shorter Oxford English Dictionary. 1973. Oxford: Oxford University Press.

Sims, V. M. 1923. 'The reliability and validity of four types of vocabulary tests.' Journal of Educational Research 20: 91-6.

Thorndike, E. L. 1924. 'The vocabularies of school pupils' in J. Carelton Bell (ed.): Contributions to Education. Vol. 1. New York: World Book Co.

Thorndike, E. L. and I. Lorge. 1944: The Teacher's Word Book of 30,000 Words. New York: Teacher's College, Columbia University.

Tilley, H. C. 1936. 'A technique for determining the relative difficulty of word meanings among elementary school children.' Journal of Experimental Education 5: 61-4.

Webster's Collegiate Dictionary. 1979. Springfield, Mass.: Merriam-Webster Inc.

Webster's Third New International Dictionary. 1961. Springfield, Mass.: MerriamWebster Inc.

Williams, H. M. 1932. 'Some problems of sampling in vocabulary tests.' Journal of Experimental Education 1:131-3.

Xue Guoyi and I. S. P. Nation. 1984. 'A university word list.' Language Learning and Communication 3:215-29.

\section{APPENDIX 1}

Vocabulary size tests

These are tests to estimate how many words you know. You will find below a list of 50 words which is part of a sample of all the words in the language. The words are arranged more or less in order of frequency, starting with common words and going down to some very unusual ones.

\section{Procedure}

1. Read through the whole list.

Put a tick next to each word you know, i.e. you have seen the word before and can express at least one meaning of it.

Put a question mark next to each word that you think you know but are not sure about.

(Do not mark the words you do not know.)

2. When you have been through the whole list of 50 words, go back and check the words with question marks to see whether you can change the question mark to a tick.

3. Then find the last five words you ticked (i.e. the ones that are furthest down the list). Show you know the meaning of each one by giving a synonym or definition or by using it in a sentence or drawing a diagram, if appropriate.

4. Check your explanations of the five words in a dictionary.

If more than one of the explanations is not correct, you need to work back through the list, beginning with the sixth to last word you ticked. Write the meaning of this word and check it in the dictionary. Continue this process until you have a sequence of four ticked words (which may include some of the original five you checked) that you have explained correctly.

5. Calculate your score for that 50-item test by multiplying the total number of known words by 500 . Do not include the words with a question mark in your scoring. 
APPENDIX 2

The 577 word Webster's Third sample divided into five tests and a list of uncommonly known words

Test 1

1 as

$2 \operatorname{dog}$

3 editor

4 shake

5 pony

6 immense

7 butler

8 mare

9 denounce

10 borough

31 comeuppance

32 downer

33 geisha

34 logistics

35 panache

36 setout

37 cervicovaginal

38 abruption

39 kohl

40 acephalia

\section{Test 2}

1 bag

2 face

3 entire

4 approve

5 tap

6 jersey

7 cavalry

8 mortgage

9 homage

10 colleague

31 detente

32 draconic

33 glaucoma

34 morph

35 permutate

36 thingamabob

37 piss

38 brazenfaced

39 loquat

40 anthelmintic
11 abstract

12 eccentric

13 receptacle

14 armadillo

15 boost

16 commissary

17 gentian

18 Iotus

19 squeamish

20 waffle

41 cupreous

42 cutability

43 regurge

44 lifemanship

45 atropia

46 sporophore

47 hypomagnesia

48 cowsucker

49 oleaginous

50 migrationist

11 avalanche

12 firmament

13 shrew

14 atrophy

15 broach

16 con

17 halloo

18 marquise

19 stationery

20 woodsman

41 gamp

42 paraprotein

43 heterophyllous

44 squirearch

45 resorb

46 goldenhair

47 axbreaker

48 masonite

49 hematoid

50 polybrid
21 aviary

22 chasuble

23 ferrule

24 liven

25 parallelogram

26 punkah

27 amice

28 chiton

29 roughy

30 barf
21 bastinado

22 countermarch

23 furbish

24 meerschaum

25 patroon

26 regatta

27 asphyxiate

28 curricle

29 weta

30 bioenvironmental 
Test 3

1 bird

2 fell

3 improve

4 barn

5 fatigue

6 kettle

7 combat

8 resent

9 redeem

10 hurrah

31 devolute

32 envoi

33 golliwog

34 neonate

35 plainchant

36 astrochemistry

37 nondurables

38 carboxyl

39 eyestalk

40 curragh

Test 4

$1 \mathrm{cool}$

2 kitchen

3 lead

4 cow

5 frog

6 scent

7 harsh

8 ascertain

9 sprig

10 matron

31 directrix

32 footage

33 horseshit

34 nighthawk

35 ravioli

36 aeroplankton

37 tandoor

38 cogito

39 corvette

40 chanterelle
11 conversion

12 fixture

13 accede

14 avocation

15 calyx

16 conclave

17 hierarchy

18 monologue

19 tamper

20 acanthus

41 gunlock

42 dipole

43 rigorism

44 localist

45 benchboard

46 stirabout

47 hypothallus

48 doombook

49 paradiplomatic

50 poroplastic

11 coronet

12 jut

13 amorphous

14 bagpipe

15 choleric

16 crock

17 incumbent

18 offal

19 untoward

20 amphitrite

41 hyperthyroid

42 pica

43 immunoassay

44 apertometer

45 scandium

46 gusli

47 chuckie

48 mendeleyevite

49 matelasse

50 slipper
21 blowout

22 crupper

23 gloaming

24 minnesinger

25 perpetuity

26 riffle

27 behindhand

28 embolism

29 angst

30 blowhard
21 carpel

22 doss

23 havelock

24 nominative

25 pilotage

26 serried

27 blurb

28 scriber

29 appositive

30 capybara 
Test 5

$\begin{array}{lll}1 \text { cotton } & 11 \text { deign } & 21 \text { centripetal } \\ 2 \text { block } & 12 \text { marrow } & 22 \text { dromedary } \\ 3 \text { precious } & 13 \text { armada } & 23 \text { ideograph } \\ 4 \text { dig } & 14 \text { boomerang } & 24 \text { nuzzle } \\ 5 \text { hostile } & 15 \text { chowder } & 25 \text { planking } \\ 6 \text { accurate } & 16 \text { earring } & 26 \text { welladay } \\ 7 \text { inhabit } & 17 \text { linguistics } & 27 \text { brassie } \\ 8 \text { crook } & 18 \text { radium } & 28 \text { huia } \\ 9 \text { blockade } & 19 \text { ventilate } & 29 \text { baobab } \\ 10 \text { microscope } & 20 \text { asperity } & 30 \text { chomp } \\ 31 \text { doubleheader } & 41 \text { isomorphy } & \\ 32 \text { fusilier } & 42 \text { gaper } & \\ 33 \text { interplay } & 43 \text { sextodecimo } & \\ 34 \text { nubile } & 44 \text { redact } & \\ 35 \text { repartition } & 45 \text { capsulectomy } & \\ 36 \text { cockup } & 46 \text { volvulus } & \\ 37 \text { saddleback } & 47 \text { mancipation } & \\ 38 \text { hairspring } & 48 \text { exceptionalism } \\ 39 \text { audivision } & 49 \text { parasternum } & \\ 40 \text { dactylology } & 50 \text { sparrowbill } & \end{array}$

Words in the Webster's Third sample that are not likely to be known

$\begin{array}{lll}\text { anamnestic } & \text { cerveliere } & \text { ominate } \\ \text { banausic } & \text { challoth } & \text { oxpecker } \\ \text { beechdrops } & \text { chinaball } & \text { palar } \\ \text { brachypterous } & \text { circumforaneous } & \text { panela } \\ \text { clinicopathologic } & \text { cladocera } & \text { parageosyncline } \\ \text { corium } & \text { clowder } & \text { patelline } \\ \text { cosmolline } & \text { coblenzion } & \text { pedalium } \\ \text { decoupage } & \text { compacta } & \text { perimetrium } \\ \text { didapper } & \text { contrist } & \text { phaeomelanin } \\ \text { disseminule } & \text { corynomorpha } & \text { phenoxybenzamine } \\ \text { enantiomorphism } & \text { cuticula } & \text { phoniatric } \\ \text { erythrism } & \text { cytozyme } & \text { pilum } \\ \text { fluerics } & \text { delomorphous } & \text { pisote } \\ \text { greylag } & \text { desmolysis } & \text { poachwood } \\ \text { hypermorph } & \text { dissilient } & \text { polyacrylate } \\ \text { jerkwater } & \text { elasmosaur } & \text { poppywort } \\ \text { kef } & \text { epornitic } & \text { porta } \\ \text { mitogenic } & \text { espinillo } & \text { propria } \\ \text { myrmecophagous } & \text { eumeces } & \text { proxenus } \\ \text { octroy } & \text { extramitochondrial } & \text { punctum } \\ \text { ouabain } & \text { fassaile } & \text { rackabones } \\ \text { pes } & \text { fluate } & \text { rohu } \\ \text { pikake } & \text { follyer } & \text { salinella } \\ \text { psychrophile } & \text { forepost } & \text { saprolegniales } \\ \text { rhus } & \text { frontad } & \text { scholarch } \\ & & \end{array}$


rubeola

sesamoiditis

smectic

supersedeas

tepa

tragacanthin

tuckahoe

yogh

advertonal

agoura

allopelagic

amphicyrtic

analogon

anthocoridae

arguendo

atacamite

authigenic

baikerinite

barsom

baya

belcher

bigarade

bostryx

boxwork

breastbeam

bungersome

burdenman

cannilan

castorile

catfit

brachium

cascabel

chicalote

crampfish

deepgoing

dioptrics

dispersoid

einkorn

endexine

erythropoiesis

fibroma

glutaraldehyde

hemal

hexamethonium

karyolymph

ketoglutarate

Iamin

linoleate

lummox garefowl

genistin

glia

goldtit

guignolet

halse

hominal

hursinghar

hydrocalumite

hydrorrhea

hypostase

incus

intocostrin

jones

kantiara

kiaat

koombar

leonite

lychnoscope

malma

manroot

melilite

meridienne

metarhodopsin

monochloramine

motacilla

nagaika

neral

nosean

okenite

cheilion

chrysogen

circannual

civilite

cloop

coaxation

cohitre

conducta

copellidine

cotyloid

curuba

cynegetic

deadheart

demivol

diphenoxylate

domnei

dungan

eminento

ervil sciurus

scudder

sella

shallon

skinball

slipe

snakefish

songman

spikebill

stremmatograph

stylogonidium

symballophone

tanonovicular

theow

tholos

tinsey

tournette

troutbird

twinspur

typicon

vashegyite

vervelle

visceripericardial

whiggamore

wobbulator

xurel

yeara

animalist

baldashin

bargeboard

palilolgy

pectoralis

pepperbush

petrolene

phano

pheoporphyrin

phyllade

pinnaglobin

pleonaste

poikilosmotic

proeutectoid

protenoid

pseudowavellite

quiebracha

roding

rotenoid

sampleite

scallom

sciara 


mooneye
notchback
osmol
playa
rachis
rhinencephalon
ruddle
scouse
snowberry
succinate
synaptosome
theca
triazine
uranic
windage
acidophilia
agammaglobulinemea
aliesterase
amgarn
amphiplatyan
anatta
ascidiozoa
aumakua
avahi
axodendrite
banstickle
bauno
beata
biunial
boughpot
breakax
brookweed
buplever
cannabinol
casualism
centumvir
cessionaire

etchant

eusynchite

extrophy

fallowchat

ferritungstite

foedaratus

fonio

frogbit

galenobismutile

gemauve

geta

groundplot

helmetpod

histocyte

howardile

huskanaw

hydrogarnet

insilicate

irreflection

jumpseed

kharmadharaya

koali

kylix

linaloe

lowa

madge

medino

merosome

metasilicate

molave

monorhinic

mouthpipe

naze

norleucine

octanoyl

orseille

ozokerite scoldenore

sealflower

senam

slipband

slurb

softa

squaloidea

strongback

sucupira

synusia

terna

thermopolymization

tinaja

tiqueur

trochantin

twatchel

tylostyle

vanaprastha

velutino

violescent

weightage

whipster

xanthydrol

xyloketose

yeatmanite 